\title{
LA EMISIÓN DE UNA ORDEN EUROPEA DE INVESTIGACIÓN PARA LA OBTENCIÓN DE PRUEBA TRANSFRONTERIZA Y SU INTRODUCCIÓN EN EL PROCESO PENAL ESPAÑOL
}

\author{
ROSER CASANOVA MARTÍ \\ Universitat Rovira i Virgili \\ roser.casanova@urv.cat \\ ELISABET CERRATO GURI' \\ Universitat Rovira i Virgili \\ elisabet.cerrato@urv.cat
}

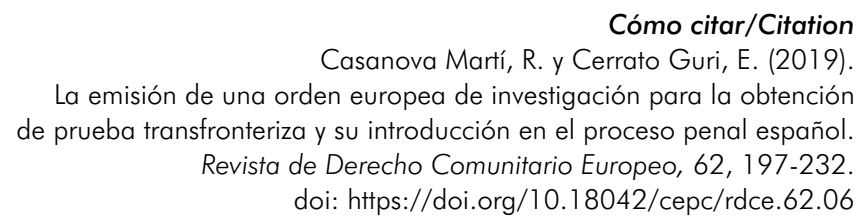

Resumen

La reciente transposición al ordenamiento jurídico español de la Directiva 2014/41/CE del Parlamento Europeo y del Consejo, de 3 de abril de 2014, relativa a la orden europea de investigación en materia penal, a través de la Ley 3/2018, de 11 de junio, por la que se modifica la Ley 23/2014, de 20 de noviembre, de reconocimiento mutuo de resoluciones penales de la Unión Europea, facilita al juez penal español la posibilidad de pedir pruebas, a la vez que practicar diligencias de investigación, a otro Estado miembro de la Unión Europea. Siendo esto así, el presente trabajo tiene por objeto realizar un análisis exhaustivo de la emisión de este novedoso

1 Profesoras de Derecho Procesal en la Universitat Rovira i Virgili. 
mecanismo de reconocimiento mutuo, así como examinar la rica problemática que plantea la admisibilidad de las pruebas obtenidas a raíz de la emisión de una orden europea de investigación para incorporar su resultado en el proceso penal español, respetando las debidas garantías del proceso judicial.

\title{
Palabras clave
}

Orden europea de investigación; admisibilidad; prueba; diligencias de investigación; cooperación judicial penal.

\section{THE ISSUANCE OF EUROPEAN INVESTIGATION ORDERS FOR CROSS-BORDER EVIDENCES AND ITS INTRODUCTION IN THE SPANISH CRIMINAL PROCEDURE}

\begin{abstract}
The recent transposition into the Spanish legal system of Directive 2014/41/ EU of the European Parliament and of the Council of 3 April 2014 regarding the European Investigation Order in criminal matters, by means of Act 3/2018 of 11 June 2018 modifying Act 23/2014 of 20 November 2014 on the mutual recognition of decisions in criminal matters in the European Union, allows the Spanish criminal courts to request other Member States of the European Union to gather evidence and carry out investigative measures. Against this background, this paper aims to carry out a comprehensive analysis of the use of this instrument of mutual recognition, as well as to examine the issues regarding the admissibility of evidence resulting from a European Investigation Order with the purpose of incorporating it into Spanish criminal proceedings, respecting the guarantees of the judicial process.
\end{abstract}

\section{Keywords}

European Investigation Order; admissibility; evidence; investigative measures; judicial cooperation in criminal matters.

\section{LA DÉLIVRANCE DES DÉCISIONS D’ENQUÊTE EUROPÉENNES POUR L'OBTENTION DES PREUVES TRANSFRONTALIÈRE ET SON INTRODUCTION DANS LA PROCÉDURE PÉNALE ESPAGNOLE}

\section{Résumé}

La transposition récente en droit espagnol de la directive 2014/41/CE du Parlement Européen et du Conseil, du 3 avril 2014, concernant l'ordre européenne en matière pénale, par le biais de la loi 3/2018, du 11 juin, qui modifie la loi 23/2014 
du 20 novembre, sur la reconnaissance mutuelle des résolutions pénales de l'Union Européenne, facilite au juge pénal espagnol la possibilité de demander des preuves, en même temps que les mesures d'enquête, dans un autre État membre de l'Union Européenne. Dans ces conditions, le présent document a pour objectif de procéder à une analyse exhaustive de la publication de ce nouveau mécanisme de reconnaissance mutuelle, ainsi que d'examiner les problèmes complexes posés par l'admissibilité des preuves obtenues suite à la publication d'un arrêté de Recherche Européen pour incorporer ses résultats dans le processus pénal espagnol, en respectant les garanties du processus judiciaire.

\section{Mots clés}

Décision d'enquête européenne; admissibilité; preuve; mesures d'enquête; coopération judiciaire en matière pénale. 


\section{SUMARIO}

I. INTRODUCCIÓN. II. APROXIMACIÓN A LA COOPERACIÓN JUDICIAL PENAL. III. LA ORDEN EUROPEA DE INVESTIGACIÓN: 1. Antecedentes. 2. Concepto y ámbito de aplicación. IV. LA EMISIÓN DE UNA OEI POR EL ESTADO ESPAÑOL: 1. Tipos de procedimientos en los que España puede emitir una OEI. 2. ¿̇Quién puede solicitar una OEI? 3. ¿Quién puede emitirla? 4. Requisitos para su emisión. 5. ¿Cómo se transmite? 6. Forma y contenido. V. INTRODUCCIÓN DE LAS PRUEBAS EN EL PROCESO PENAL ESPAÑOL: 1. Aplicación de las normas de derecho interno. 2. Cauce procesal para introducir las medidas de investigación al proceso penal: 2.1. La vía del art. 730 LECrim. 2.2. Su aplicación a las medidas de investigación derivadas de una OEI. 3. Admisibilidad de las pruebas derivadas de una OEI. VI. CONCLUSIONES. BIBLIOGRAFía.

\section{INTRODUCCIÓN}

La cada vez más habitual existencia de criminalidad transnacional, sobre todo tras los atentados terroristas de los últimos años perpetrados en el territorio de la Unión Europea y el incremento alarmante de la delincuencia organizada hacen imprescindible la más estrecha colaboración entre los Estados miembros en este ámbito. Para dar solución a este grave problema, el legislador europeo ha activado diferentes mecanismos de cooperación judicial en materia penal, siendo de destacar la orden europea de investigación (OEI, en adelante), que tiene como principal finalidad la obtención de prueba transfronteriza. A este instrumento de reconocimiento mutuo, que se encuentra regulado en la Directiva 2014/41/CE ${ }^{2}$, dedicamos el presente estudio por la relevancia que tiene la prueba en la enervación de la presunción de inocencia para fundamentar una sentencia de condena.

España ha transpuesto recientemente esta directiva, integrándola así en su ordenamiento jurídico. Para ello ha optado por su regulación en la ya existente Ley 23/2014, de 20 de noviembre, de reconocimiento mutuo de

2 Directiva 2014/41/CE del Parlamento Europeo y del Consejo, de 3 de abril de 2014, relativa a la orden europea de investigación en materia penal (DO L 130, de 1 de mayo de 2014, p. 1). 
resoluciones penales en la Unión Europea, junto con el resto de mecanismos previstos sobre esta materia, obviando de este modo su incorporación en la Ley de Enjuiciamiento Criminal.

Este panorama legislativo contempla la posibilidad de que un juez español pueda emitir y ejecutar órdenes europeas de investigación. Así, se configurará como autoridad de emisión cuando en el transcurso del proceso penal se vea en la necesidad de pedir colaboración para practicar una medida de investigación o una prueba en otro Estado del espacio de la UE. Por su parte, será autoridad de ejecución cuando la necesidad antes indicada proceda de otro Estado miembro que pretenda la colaboración de las autoridades judiciales españolas para practicar pruebas o medidas de investigación en España. Y de estos dos supuestos centramos la atención de nuestro trabajo en el primero de los señalados por la rica y múltiple problemática que plantea la admisibilidad de la prueba derivada de una OEI emitida por un juez español que quiera incorporar su resultado en el proceso penal del que esté conociendo.

\section{APROXIMACIÓN A LA COOPERACIÓN JUDICIAL PENAL}

Una de las principales consecuencias de la creación del Espacio de Libertad, Seguridad y Justicia (ELSJ) de la UE, reconocido en el art. 3 TUE y desarrollado en el título V del TFUE (arts. 67 a 89), es la materialización de políticas de cooperación judicial, tanto en materia civil como en materia penal (Jimeno Bulnes, 2011: 25-32) para articular un derecho procesal europeo, siempre, en términos del propio art. 67.1 TFUE, «dentro del respeto a los derechos fundamentales y de los distintos sistemas y tradiciones jurídicas de los Estados miembros».

En concreto, la cooperación judicial en materia penal, desarrollada en el capítulo 4 del título antes mencionado del TFUE (arts. 82 a 86) reposa sobre la base de dos ejes fundamentales: el principio de reconocimiento mutuo de las sentencias y de las resoluciones judiciales, siendo este principio el elemento clave de la cooperación judicial en materia penal en la Unión desde el Consejo Europeo de Tampere de 15 y 16 de octubre de $1999^{3}$; y la aproximación

3 Considerando segundo de la Directiva 2014/41. Este principio se implanta en el espacio de la UE con la orden europea de detención y entrega, regulada en la Decisión Marco del Consejo 2002/584/JAI, de 13 de junio de 2002, relativa a la orden de detención europea y a los procedimientos de entrega entre Estados miembros (DO L 190, de 18 de julio de 2002, p. 1) que, en palabras de García Sánchez (2012: 192) «viene a sustituir a los tradicionales procedimientos de extradición entre los Estados miembros de la UE». El principio de reconocimiento mutuo ha sido expresamente 
legislativa (Bachmaier Winter, 2016: 3). Así expresamente lo ha reconocido la jurisprudencia del TJUE ${ }^{4}$ en referencia a la Orden Europea de Detención, a la que se ha referido como «primera concreción en el ámbito del Derecho penal del principio del reconocimiento mutuo que el Consejo Europeo ha calificado como "piedra angular" de la cooperación judicial».

El principio de reconocimiento mutuo, basado en la confianza recíproca de los Estados de la UE, y que tiene su origen en la creación de un mercado único comunitario ante la diversidad de legislaciones (Martín y Bujosa, 2016: 23), implica que las resoluciones dictadas por las autoridades competentes de los Estados miembros sean directamente reconocidas y ejecutadas en cualquier otro Estado de la Unión, salvo cuando concurra alguno de los motivos que permita suspender o denegar su reconocimiento ${ }^{5}$. De este modo se atribuye «eficacia directa a las resoluciones de un órgano judicial en los demás Estados miembros de la Unión Europea, sin un previo proceso de homologación y sin control del Estado de ejecución de los presupuestos que dan lugar a la resolución» (Bachmaier Winter, 2016: 4) ${ }^{6}$, lo que ha supuesto una auténtica revolución en las relaciones de cooperación entre los Estados miembros ${ }^{7}$. A pesar de ello, el TJUE ha admitido la posible limitación de este principio, así como el de confianza mutua, entre los Estados miembros en circunstancias

estudiado por la doctrina procesal, destacando, entre otros, Arangüena Fanego (2010: 224).

4 Sentencia de 29 de junio de 2017, Poplawski, C-579/15, EU:C:2017:503. Del mismo modo se pronuncia la Sentencia de 25 enero de 2017, Vilkas, C-640/15, EU:C:217:39, al establecer que «es jurisprudencia reiterada del Tribunal de Justicia que el principio de reconocimiento mutuo, que constituye la "piedra angular» de la cooperación judicial, implica, con arreglo al art.1, apdo. 2, de la Decisión Marco (LCEur 2002, 1985), que, en principio, los Estados miembros están obligados a ejecutar una orden de detención europea». Y, más recientemente, véase la Sentencia de 5 de julio de 2018, Bertold Lada, C-390/16, EU:C:2018:532.

5 A este principio, y en relación con la orden europea de detención y entrega, se ha referido la Sentencia de 11 de enero de 2017, Grundza, C-289/15, EU:C:2017:4, en los siguientes términos: «El principio de reconocimiento mutuo implica que la autoridad competente del Estado de ejecución, en principio, reconocerá la sentencia que le ha sido transmitida y adoptará sin dilación las medidas necesarias para la ejecución de la condena».

6 En la misma línea lo definen Martín y Bujosa (2016: 25).

7 Apdo. I del preámbulo de la Ley 23/2014, de 20 de noviembre, de reconocimiento mutuo de resoluciones penales en la Unión Europea (BOE 282, de 21 de noviembre de 2014, p. 95437). 
excepcionales, tal y como pone de relieve la Gran Sala en su reciente sentencia de 23 de enero de $2018^{8}$.

Para dar cumplimiento a este principio, España aprobó la Ley 23/2014, de 20 de noviembre, de reconocimiento mutuo de resoluciones penales en la Unión Europea, configurando de este modo un instrumento integrador que «responde al compromiso de mejora de la cooperación judicial penal en la Unión Europea y la lucha contra la criminalidad, garantizando la seguridad y los derechos de los ciudadanos como fin irrenunciable del Estado»'. En particular, en su art. 1 establece que las autoridades judiciales competentes puedan emitir y transmitir una orden o resolución de las contempladas en el art. 2 de la propia ley a otro Estado miembro - para su reconocimiento y ejecución en dicho Estado-, así como reconocer y ejecutar ordenes europeas y resoluciones penales correctamente emitidas por la autoridad competente de otro Estado miembro.

\section{LA ORDEN EUROPEA DE INVESTIGACIÓN}

Para facilitar dicho reconocimiento mutuo, que como hemos señalado tiene su base en la confianza mutua de los Estados, el apdo. segundo del art. 82 TFUE reconoce competencias legislativas al Parlamento Europeo y al Consejo para adoptar directivas que incorporen normas mínimas en aras a alcanzar la «cooperación policial y judicial en asuntos penales con dimensión transfronteriza» (Bachmaier Winter, 2016: 2) que, necesariamente, y en la línea de la genérica redacción del art. 67.1 TFUE, «deberán tener en cuenta las diferencias entre las tradiciones y los sistemas jurídicos de los Estados miembros», favoreciendo la aproximación — que no armonización- de las distintas legislaciones de la $\mathrm{UE}^{10}$. En este punto debe indicarse que la aplicación del principio de reconocimiento mutuo en el ámbito penal - tanto material como procesal - ha sido mucho más costosa que en el civil. Por ello, para avanzar en la cooperación judicial penal, cobra sentido la afirmación de Jimeno Bulnes (2011: 34-35), relativa a «la ventaja de la aproximación respecto a la armonización» legislativa, pues, del mismo modo que la armonización,

Asunto C-367/16, EU:C:2018:27.

Apdo. XVI de la Ley 23/2014.

10 Téngase en cuenta que, en virtud de lo dispuesto en el art. 82.2 in fine TFUE, la adopción de las referidas normas mínimas no supondrá óbice alguno para que los Estados miembros que lo consideren puedan mantener o instaurar «un nivel más elevado de protección de las personas». 
la aproximación «exige la convergencia en un objetivo común desde ordenamientos jurídicos nacionales diversos» pero, en cambio, "permite conservar a cada uno de ellos su singularidad $»^{11}$. De hecho, este es el criterio que finalmente ha seguido el legislador europeo en la materia que ahora nos ocupa.

Esta vocación de la actual norma de funcionamiento de la UE ha dado lugar al nacimiento de diversos instrumentos de reconocimiento mutuo, que se han desarrollado con éxito bajo la forma de orden europea o resolución. Un claro ejemplo de ello es la OEI, regulada en la Directiva 2014/41/CE del Parlamento Europeo y del Consejo, de 3 de abril de 2014, relativa a la orden europea de investigación en materia penal y que el Estado español ha incorporado recientemente a su ordenamiento jurídico interno a través de la Ley 3/2018, de 11 de junio, por la que se modifica la Ley 23/2014, de 20 de noviembre, de reconocimiento mutuo de resoluciones penales de la Unión Europea, para regular la $\mathrm{OEI}^{12}$. A este instrumento de reconocimiento mutuo dedicamos el posterior desarrollo de nuestro estudio.

\section{ANTECEDENTES}

En respuesta al objetivo marcado en el Programa de Estocolmo - adoptado por el Consejo Europeo en diciembre de $2009-13$ de crear un sistema

11 Y, más recientemente, véase Jimeno Bulnes (2016: 195). En cambio, más partidaria de la armonización de los sistemas penales y procesales de los Estados miembros, sobre todo por la experiencia derivada de la implantación de la orden europea de detención y entrega, se ha manifestado García Sánchez (2012: 194- 203), aún siendo consciente de los importantes cambios derivados la entrada en vigor del Tratado de Lisboa ( 1 de diciembre de 2009), que no acaban de limar las «divergencias entre los Estados en cuanto a la delimitación de lo delictivo», ni tampoco la "diversidad en la interpretación de los derechos fundamentales reconocidos en las distintas normas del Derecho Europeo y de los derechos nacionales».

12 BOE 142, de 12 de junio de 2018, p. 60161. Además de la referida OEI, el art. 2 de la Ley 23/2014 regula los siguientes instrumentos de reconocimiento mutuo: la orden europea de detención y entrega, la resolución por la que se impone una pena o medida privativas de libertad, la resolución de libertad vigilada, la resolución sobre medidas de vigilancia de la libertad provisional, la orden europea de protección, la resolución de embargo preventivo de bienes o de aseguramiento de pruebas, la resolución de decomiso y la resolución por la que se imponen sanciones pecuniarias. Todos ellos han sido objeto de consideración por Bachmaier Winter (2016: 20-24).

13 DO C 115 , de 4 de mayo de 2010, p. 4. En concreto, este programa «establece las prioridades de la Unión Europea (UE) respecto al espacio de libertad, seguridad y justicia durante el periodo 2010 - 2014. Partiendo de los logros de sus predecesores, 
general para obtener pruebas en los casos de dimensión transfronteriza, bajo el principio de reconocimiento mutuo, nace la directiva que instaura la OEI con el objetivo de unificar la fragmentada «regulación» habida hasta el momento $^{14}$.

Antes de la entrada en vigor de la directiva, la materia probatoria en el ámbito europeo se encontraba dispersa e incompletamente regulada en las dos siguientes decisiones marco: la escasamente utilizada Decisión Marco 2003/577/JAI del Consejo, de 22 de julio de 2003, relativa a la ejecución en la Unión Europea de las resoluciones de embargo preventivo de bienes y de aseguramiento de pruebas ${ }^{15}$, que tenía por objeto la prevención de la destrucción, transformación, desplazamiento o enajenación de pruebas, si bien limitada a la fase de embargo; y la Decisión Marco 2008/978/JAI del Consejo, de 18 de diciembre de 2008, relativa al exhorto europeo de obtención de pruebas para recabar objetos, documentos y datos destinados a procedimientos en materia penal ${ }^{16}$, únicamente aplicable a la prueba ya existente, dejando de lado las medidas de investigación ${ }^{17}$.

La coexistencia de múltiples instrumentos basados en diferentes principios — básicamente, asistencia mutua y reconocimiento mutuo — tenía como consecuencia su confusa utilización en la obtención de prueba, en detrimento de una apropiada cooperación judicial penal transfronteriza. Consciente de esta realidad, la Comisión Europea presentó el 11 de noviembre de 2009 el «Libro Verde sobre la obtención de pruebas en materia penal en otro Estado

los programas de Tampere y La Haya, pretende hacer frente a los desafíos del futuro y reforzar aún más el espacio de libertad, seguridad y justicia, con medidas centradas en los intereses y las necesidades de los ciudadanos».

14 De esta fragmentación se hace eco, no solo respecto a la obtención de pruebas, sino a la genérica cooperación judicial penal, Jimeno Bulnes (2011: 92-116). Por otro lado, véase el considerando sexto de la directiva, el preámbulo II de la Ley 3/2018 y el Dictamen 1/17 de la fiscal de Sala de Cooperación Penal Internacional sobre el régimen legal aplicable debido a la no transposición en plazo de la directiva de la OEI y sobre el significado de la expresión «disposiciones correspondientes» que sustituye dicha directiva. Disponible en: https://bit.ly/2GO7ynr.

15 DO L 196, de 2 de agosto de 2003, p. 45.

16 DO L 350, de 30 de diciembre de 2008, p. 72.

17 Este limitado ámbito de aplicación del exhorto europeo de obtención de pruebas explicaba, como pone de manifiesto el considerando 4, el recurso de las autoridades competentes «a los procedimientos de asistencia judicial que siguen siendo de aplicación en todos los casos en los que las pruebas no están incluidas en el ámbito de la $\mathrm{EEP».} \mathrm{A} \mathrm{mayor} \mathrm{abundamiento} \mathrm{véase} \mathrm{Bachmaier} \mathrm{Winter} \mathrm{(2011:} \mathrm{2-5).}$ 
miembro y sobre la garantía de su admisibilidad ${ }^{18}$ con la finalidad, por un lado, de proponer una solución más eficaz que sustituyera el hasta entonces vigente régimen jurídico sobre obtención de pruebas en materia penal por un nuevo y único instrumento basado en el principio del reconocimiento mutuo que cubriera, además de las pruebas existentes, las diligencias de investigación; y, por otro lado, confirmar su validez, a través de una consulta, a los Estados miembros.

Una vez finalizado el período de consulta —el 22 de enero de 2010_, a iniciativa de siete Estados miembros, entre ellos España, se remitió al Parlamento y al Consejo una propuesta de directiva de orden europea de investigación ${ }^{19}$, que se materializó con la aprobación de la Directiva 2014/41/CE, tal y como había marcado el Programa de Estocolmo en su punto 3.1.1., dedicado a fomentar la aplicación del principio de reconocimiento mutuo en materia penal ${ }^{20}$. Aunque la directiva exigía (art. 36.1) su transposición por los Estados miembros, a más tardar, el 22 de mayo de 2017, España ha tardado más de un año, desde la indicada fecha límite, en cumplir con este deber ${ }^{21}$.

18 «Libro Verde de la Comisión Europea sobre la obtención de pruebas en materia penal en otro Estado miembro y sobre la garantía de su admisibilidad», COM (2009) 624 final, 11-11-09.

19 Iniciativa del Reino de Bélgica, la República de Bulgaria, la República de Estonia, el Reino de España, la República de Austria, la República de Eslovenia y el Reino de Suecia con vistas a la adopción de una Directiva del Parlamento Europeo y del Consejo de ... relativa al exhorto europeo de investigación en materia penal (2010/C 165/02). Disponible en: https://bit.ly/2Tp5Uyo.

20 «El Consejo Europeo considera que debe proseguirse la creación de un sistema general para obtener pruebas en los casos con dimensión transfronteriza, basado en el principio de reconocimiento mutuo. Los instrumentos existentes en este ámbito constituyen un sistema fragmentario. Es necesario un nuevo planteamiento, basado en el principio de reconocimiento mutuo, pero que tenga también en cuenta la flexibilidad del sistema tradicional de asistencia judicial. Este nuevo modelo podría tener un alcance más amplio y debería cubrir tantos tipos de pruebas como sea posible, teniendo en cuenta las medidas de que se trate». A este punto hacen también referencia Martín y Bujosa (2016: 115-116).

21 El incumplimiento de este precepto por parte del Estado español y la derogación de la Decisión Marco 2008/978/JAI sobre el exhorto europeo de obtención de pruebas en virtud del Reglamento 2016/95, de 20 de enero de 2016, por el que se derogan determinados actos en materia de cooperación judicial y policial en materia penal (DO L 26, de 2 de febrero de 2016, p. 9) motivó que la Fiscalía General del Estado (concretamente su Unidad de Cooperación Internacional) emitiese un dictamen con fecha 19 de mayo de 2017 para establecer pautas básicas y transitorias sobre la interpretación de la OEI por los fiscales en tanto no fuera publicada la ley española de 


\section{CONCEPTO Y ÁMBITO DE APLICACIÓN}

Del análisis conjunto del art. 1 de la directiva y del art. 186.1 de la Ley 23/2014 podemos definir la OEI como el instrumento de cooperación judicial penal que adopta la forma de una resolución judicial emitida o validada por la autoridad judicial competente, que permite a un Estado miembro (el que emite y transmite la orden) pedir pruebas y/o diligencias de investigación a otro Estado miembro (el que reconoce y ejecuta la orden) para, posteriormente, poderlas incorporar a su proceso penal interno ${ }^{22}$.

En concreto, su finalidad es alcanzar uno o ambos de los siguientes propósitos: a) practicar una o más medidas de investigación para la obtención de pruebas en otro u otros Estados miembros; y/o b) obtener pruebas que ya obren en poder de las autoridades competentes del Estado de ejecución. Asimismo, la directiva ha querido incluir la posibilidad de utilizar la OEI para adoptar cualquier medida de investigación destinada a impedir de forma cautelar la destrucción, transformación, desplazamiento, transferencia o enajenación de un objeto que pudiera emplearse como prueba (art. 32 de la directiva) $)^{23}$.

De este modo, se pone de manifiesto que el legislador europeo ha querido ir más allá de la mera obtención de pruebas ya existentes ${ }^{24}$, introduciendo,

transposición (Dictamen 1/17 de la fiscal de Sala de Cooperación Penal Internacional sobre el régimen legal aplicable debido a la no transposición en plazo de la directiva de la orden europea de investigación y sobre el significado de la expresión «disposiciones correspondientes» que sustituye dicha directiva). Finalmente ha entrado en vigor el 1 de julio de 2018 (disposición final sexta de la Ley 3/2018, de 11 de junio).

Sobre el concepto de la OEI véanse también, entre otros, Bachmaier Winter (2016: 22); Burgos Ladrón de Guevara (2016: 521), y Martínez García (2016: 52).

De ello se percata también Jimeno Bulnes (2016: 164).

24 Siguiendo a Martínez García (2016: 52), la nueva OEI se diferencia del exhorto europeo de obtención de pruebas (EEP) — regulado por la ya derogada (art. 34.2 de la directiva) Decisión Marco 2008/978/JAI - en el hecho de que a través de este no se solicitaban medidas de investigación sino pruebas y datos que se hallaban en poder del país de ejecución. Según la autora, la diferencia entre ambos instrumentos es "cualitativamente muy importante, pues este instrumento — refiriéndose al EEP — es muy inferior a lo que supone la orden europea de investigación, donde un juez le dice a otra autoridad lo que debe de hacer para colaborar». En esta línea, Jimeno Bulnes (2016: 152-153) matiza «la vocación de provisionalidad» del exhorto por su reducido ámbito de aplicación, restringido al «reconocimiento de resoluciones jurisdiccionales dictadas con el fin de reunir (y en su caso remitir) tales objetos, documentos o datos destinados a ser utilizados en un proceso penal pendiente en diferente Estado miem- 
como significativa novedad, la práctica de medidas de investigación transfronterizas, permitiéndose de esta forma la colaboración entre los Estados miembros durante cualquier fase del proceso penal ${ }^{25}$, lo que sin duda debemos aplaudir.

En relación con el ámbito de aplicación, tanto la norma europea como la estatal (arts. 3 y 186.3, respectivamente) son claras al establecer que la OEI comprende "todas las medidas de investigación», con la única excepción de la creación de un equipo conjunto de investigación y la obtención de pruebas en dicho equipo ${ }^{26}$. A pesar de ello, tal y como plantea cierta doctrina autorizada (Jimeno Bulnes, 2016: 170-171), la directiva no concreta qué se entiende por medida de investigación, lo que puede plantear dudas a los Estados miembros que deban practicar una medida que no esté prevista en su legislación interna. En cambio, de lo que sí se ha preocupado el legislador es de añadir normas adicionales que contemplan un régimen específico - arts. 22 a 31 de la directiva - para determinadas medidas de investigación ${ }^{27}$.

bro, sin contemplar cualesquiera otros medios probatorios más allá de éste de carácter documental». Igualmente se pronuncia Bachmaier Winter (2011: 5-7), quien añade que una de las consecuencias del incompleto contenido del EEP era que "para cualquier otra petición probatoria los fiscales y jueces habrán de cursar la correspondiente rogatoria conforme a los convenios de asistencia judicial de 1959 y de 2000». Por último, sobre la ineficacia del anterior EEP, por cubrir solo elementos de prueba, véase también Martín y Bujosa (2016: 23, 117-122).

25 Ténganse en cuenta el considerando 25 de la directiva y el preámbulo II. 5 de la Ley 3/2018.

26 Así lo ha establecido el art. 13 del Convenio relativo a la asistencia judicial en materia penal entre los Estados miembros de la Unión Europea (Convenio celebrado por el Consejo de conformidad con el art. 34 del TUE-DO C 197, de 12 de julio de 2000, p. 1) y la Decisión Marco 2002/465/JAI del Consejo, de 13 de junio de 2002, sobre equipos conjuntos de investigación (DO L 162, de 20 de junio de 2002, p. 1), salvo a efectos de la aplicación respectivamente del art. 13.8 del convenio y del art. 1.8 de la decisión marco. En opinión de Martínez García (2016: 55), ha sido una lástima que no se haya logrado consenso suficiente para regular en la propia directiva los equipos de investigación conjunta, al entender que es «lo más adecuado, eficiente y seguro para obtener una prueba en condiciones de licitud». A mayor abundamiento sobre los equipos conjuntos de investigación, si bien con relación a la trata de seres humanos, véase García García (2018: 15-19).

27 Estas son el traslado temporal de detenidos, las comparecencias por teléfono o videoconferencia, la obtención de información relacionada con cuentas o transacciones bancarias, la obtención de pruebas en tiempo real, las entregas vigiladas o las investigaciones encubiertas y la intervención de telecomunicaciones. Sobre las medidas específicas véanse Martínez García (2016: 87-109) y Jimeno Bulnes (2016: 184-191). 


\section{LA EMISIÓN DE UNA OEI POR EL ESTADO ESPAÑOL}

En España, una autoridad judicial puede emitir una OEI —configurándose como Estado de emisión (art. 2.c de la directiva) - cuando lo que pretenda sea practicar medidas de investigación y/u obtener pruebas transfronterizas, dentro del espacio de la UE, para introducirlas en el proceso penal español; y, a su vez, puede también reconocer y ejecutar una OEI — configurándose en esta ocasión como Estado de ejecución (art. 2.d de la directiva) - remitida por otro Estado miembro cuando quien la emita pretenda la práctica de medidas de investigación y/o la obtención de pruebas en España para su incorporación al proceso que corresponda del Estado emisor. De estas dos posibles situaciones, es objeto principal de nuestro trabajo centrarnos en la primera de las descritas, esto es, en la emisión por parte del Estado español de una OEI.

\section{TIPOS DE PROCEDIMIENTOS EN LOS QUE ESPAÑA PUEDE EMITIR UNA OEI}

Una de las cuestiones a tener en cuenta para la emisión de una OEI es determinar en qué procesos puede aplicarse. La solución al respecto la encontramos tanto en la directiva (art. 4) como en la Ley 23/2014 (art. 186.2). En concreto, la directiva establece su aplicación en procedimientos penales, pero también la extiende a otros procedimientos incoados por autoridades administrativas, cuando su decisión pueda dar lugar a un procedimiento en materia penal, teniendo en cuenta, como indica Martínez García (2016: 56), que existen ordenamientos jurídicos «donde el proceso administrativo ocupa una mayor dimensión procesal, como ámbito sancionador que linda con el proceso penal».

Por su parte, la ley española, en su art. 186.2, hace asimismo referencia a ambos procedimientos, esto es, el penal y el administrativo. Sin embargo, la lectura atenta de este precepto nos permite advertir que en realidad se está refiriendo a los procedimientos incoados por las autoridades competentes de otros Estados miembros, siendo a nuestro entender únicamente aplicable este artículo cuando España es Estado de ejecución. Por ello es imprescindible conectar esta norma con el art. 187 del mismo cuerpo legal, del que se desprende que las autoridades competentes españolas solo podrán emitir una OEI en el marco de un proceso penal ${ }^{28}$.

28 En este contexto, debe tenerse en cuenta, como señala Martínez García (2016: 56), que en el caso de España «no es de aplicación por la razón que nuestro proceso administrativo da lugar a un recurso ante lo contencioso administrativo y no en un proceso penal». 


\section{2. ¿̇QUIÉN PUEDE SOLICITAR UNA OEI?}

Antes de la aprobación de la directiva no existía instrumento alguno que permitiera al investigado o acusado la posibilidad de solicitar pruebas de índole transnacional para su defensa, siendo la única opción para ellos la disposición de recursos económicos suficientes para su obtención ${ }^{29}$. Esta ausencia provocaba un injustificado desequilibrio entre las partes procesales en beneficio de la acusación, quien veía colmada la necesidad de obtención de prueba transfronteriza por la labor de acusación pública del Ministerio Fiscal. Este desequilibrio se subsana con la introducción del apdo. tercero del art. 1 de la directiva, que, a diferencia del texto de propuesta anterior, reconoce expresamente "a una persona sospechosa o acusada» la posibilidad de solicitar la emisión de una $\mathrm{OEI}^{30}$. De este modo, se evidencia la posibilidad de solicitar una OEI tanto de oficio por el órgano judicial como por cualquiera de las partes inmersas en un proceso penal ${ }^{31}$.

\section{3. ¿̇QUÉN PUEDE EMITIRLA?}

En virtud de lo establecido en el art. 2 c) de la directiva podrá ser autoridad de emisión: «a) un juez, órgano jurisdiccional, juez de instrucción

29 Así se constata en la Iniciativa del Reino de Bélgica, la República de Bulgaria, la República de Estonia, el Reino de España, la República de Austria, la República de Eslovenia y el Reino de Suecia con vistas a la adopción de una Directiva del Parlamento Europeo y del Consejo de ... relativa al exhorto europeo de investigación en materia penal (2010/C 165/02), disponible en: https://bit.ly/2Tp5Uyo . En este punto es interesante destacar lo que señalaba Bachmaier Winter (2011: 11), antes de la entrada en vigor de la directiva, en relación con la necesidad de aprobar, previamente a la OEI, «un instrumento europeo que defina de manera uniforme las garantías procesales mínimas que han de respetarse en todo proceso penal», al entender que, con la aprobación de este instrumento que favorece la transmisión de pruebas entre autoridades judiciales, se incrementa el desequilibrio entre la parte acusadora y la parte acusada.

30 En esta línea Bachmaier Winter (2016: 22) señala que ello permite «equilibrar la desigualdad en el acceso a la prueba transnacional entre acusación y defensa».

31 Asimismo lo reconoce Martínez García (2016: 53), cuando indica que «en materia de legitimación activa para solicitar una OEI se estará a lo que determinen las normas nacionales, pero con toda seguridad se podrá solicitar de oficio por la autoridad judicial, a instancia de la parte acusadora o del Ministerio Fiscal y a instancia de la parte imputada o acusada o su abogado, como parte del derecho de defensa». 
o fiscal competente en el asunto que se trate; o b) cualquier otra autoridad competente según la defina el Estado de emisión que, en el asunto específico de que se trate, actúe en calidad de autoridad de investigación en procesos penales y tenga competencia para ordenar la obtención de pruebas con arreglo al Derecho nacional». En este segundo supuesto, el legislador europeo exige, antes de su transmisión a la autoridad de ejecución, la validación de la OEI por una autoridad judicial, quien previamente deberá controlar el cumplimiento de los requisitos para su emisión de conformidad con la directiva —en particular las condiciones establecidas en el art. 6.1-. Por lo tanto, en última instancia, la emisión de una OEI depende, en todo caso, de una autoridad judicial, ya sea porque es ella quien la emite directamente o porque la acaba validando ${ }^{32}$.

En su caso, la Ley 23/2014 reconoce, en su art. 187.1, como autoridades competentes para emitir, pero también para ejecutar ${ }^{33}$, una OEI en España tanto a los órganos judiciales penales como al Ministerio Fiscal, con las siguientes matizaciones.

Por un lado, se atribuye competencia a los jueces del proceso penal en el que debe adoptarse la medida de investigación, esto es, los que conozcan de la fase de instrucción; y también los jueces o tribunales que hayan admitido la prueba si el procedimiento se encuentra en fase de enjuiciamiento.

Por otro lado, reciben también la consideración de autoridad de emisión los fiscales en los procedimientos que dirijan, siempre que la medida que contenga la OEI no sea limitativa de derechos fundamentales. En este punto, nos atrevemos a decir que no es realista la atribución a los fiscales de la competencia para emitir una OEI, ya que, de momento, en nuestro ordenamiento jurídico la instrucción sigue en manos del órgano judicial —salvo para el proceso penal contra menores de la LO 5/2000, de 12 de enero, reguladora de la responsabilidad penal de los menores ${ }^{34}$, en cuyo art. 6 se reconoce expresamente la dirección de la investigación de los hechos al Ministerio Fiscal$\mathrm{Si}$ bien es cierto que los fiscales pueden iniciar el proceso penal y participar

32 Jimeno Bulnes (2016: 174-176) critica que una autoridad distinta a la judicial pueda autorizar una medida de investigación «si posee competencia para ello en el Estado de emisión de que se trate», por ejemplo, una autoridad policial o administrativa. En nuestra opinión, ello lo soluciona la propia directiva al exigir que en estos casos la OEI sea validada por una autoridad judicial.

33 Si bien la autoridad competente para recibir una OEI es el Ministerio Fiscal, quien deberá remitirla a la autoridad judicial competente en caso de que la medida solicitada sea limitativa de derechos fundamentales, de acuerdo con el art. 187.2 de la Ley 23/2014.

34 BOE 11, de 13 de enero de 2000, p. 1422. 
como acusadores públicos de la instrucción, debemos ahora recordar que el legislador no aprovechó la reforma de la Ley de Enjuiciamiento Criminal de 2015 para otorgarles la dirección de la instrucción ${ }^{35}$.

\section{REQUISITOS PARA SU EMISIÓN}

Para que un juez español pueda emitir una OEI deberá tener en cuenta los siguientes dos requisitos, previstos tanto en la directiva como en la Ley 23/2014 (arts. 6 y 189, respectivamente). En primer lugar, deberá estar a los principios de necesidad y proporcionalidad, de manera que la medida de investigación que se pretenda practicar, y que ha motivado la emisión de la OEI, sea acorde a los fines del procedimiento para el que se solicita. Y, en segundo lugar, que tal medida de investigación pudiera haber sido dictada en las mismas condiciones en un caso interno español similar.

Respecto de los principios de proporcionalidad y necesidad, entendemos que deben tenerse especialmente en cuenta cuando la medida de investigación cuya práctica se pretende en el Estado de ejecución sea limitativa de derechos fundamentales.

Por lo que atañe a estos principios, la doctrina es consciente de su difícil definición, más aún teniendo en cuenta, como indica Bachmaier Winter (2016: 23), la complejidad de «elaborar un concepto armonizado a nivel europeo» y el silencio de la directiva sobre esta cuestión ${ }^{36}$. Siendo esto así, y ante la ausencia de previsión legal alguna — tampoco a nivel nacional- que lo concrete, al juez español no le quedará más opción que acudir a la doctrina jurisprudencial para valorar en cada concreto caso si se cumple con la exigida proporcionalidad y necesidad antes de emitir una OEI. Así, y en relación con el principio de proporcionalidad, nuestro Tribunal Constitucional (TC)

35 Este reconocimiento a los fiscales como directores de la investigación sí que se contenía en el Anteproyecto de Ley de Enjuiciamiento Criminal de 2011 — disponible en: https://bit.ly/2GQGuUI-y en el Borrador de Código Procesal Penal de 2013. Sobre estas propuestas de reforma de la LECrim, Casanova Martí (2014: 358) indica que «ambas reformas van por la misma línea, con una serie de cambios significativos de la estructura del proceso penal, entre las que destaca la asunción de la dirección de la investigación por el Ministerio Fiscal».

36 Ante esta realidad, la autora apunta que para el principio de proporcionalidad debería valorarse: «la gravedad del delito, la necesidad de la prueba para la investigación y el enjuiciamiento del mismo, la inexistencia de otra medida menos lesiva para alcanzar el mismo fin, las consecuencias de la adopción de la medida para el o los sujetos afectados, y por último si la medida es proporcionada a los fines del proceso». 
destaca la importancia de explicitar en el momento de adoptar la medida «todos los elementos indispensables para realizar el juicio de proporcionalidad y para hacer posible su control posterior, en aras del respeto del derecho de defensa del sujeto pasivo de la medida", lo que explica que a tal fin «el órgano judicial debe exteriorizar los datos o hechos objetivos que pueden considerarse indicios de la existencia del delito y de la conexión de la persona o personas investigadas con el mismo; indicios que han de ser algo más que simples sospechas (SSTC 167/2002, de 18 de septiembre, FJ 2; 184/2003, de 23 de octubre, FJ 11; y 197/2009, de 28 de septiembre, FJ 4)» ${ }^{37}$. Y el Tribunal Superior (TS) sintetiza como presupuestos del juicio de proporcionalidad los hechos o datos objetivos que puedan considerarse indicios sobre «1) la existencia de un delito; 2) que éste sea grave; y 3) sobre la conexión de los sujetos que puedan verse afectados por la medida con los hechos investigados» ${ }^{38}$.

En cuanto al principio de necesidad el TC ha señalado que «todo acto o resolución que limite derechos fundamentales ha de asegurar que las medidas limitadoras sean necesarias para conseguir el fin perseguido» ${ }^{39}$, respecto a lo cual el TS ha matizado que "la necesidad de la medida significa que solo debe acordarse cuando, desde una perspectiva razonable, no estén a disposición de la investigación, en atención a sus características, otras medidas menos gravosas para los derechos fundamentales del investigado e igualmente útiles para la investigación $»^{40}$.

37 Sentencia del Tribunal Constitucional de 22 de septiembre de 2014, 145/2014, ES:TC:2014:145, FJ 2. En esta misma línea lo recuerda el Tribunal Supremo en su reciente Sentencia de 19 febrero de 2018, 86/2018, RJ 2018\1029, ES:TS:2018:569, FJ 13. Sobre la suficiencia de estos indicios, con cita a diversas sentencias del TEDH (caso Ludï contra Suiza, de 15 de junio de 1992; caso Klass y otros contra Alemania, de 6 de septiembre de 1978) se pronuncia la trascendente sentencia del Tribunal Constitucional de 5 de abril de 1999 , FJ 8, que requiere que «existan datos fácticos o indicios que permitan suponer que alguien intenta cometer, está cometiendo o ha cometido una infracción grave o donde existan buenas razones o fuertes presunciones de que las infracciones están a punto de cometerse, o en otros términos, algo más que meras sospechas, pero también algo menos que los indicios racionales que se exigen por el art. 384 LECrim para el procesamiento».

Por todas, véase la Sentencia del Tribunal Supremo de 22 de julio de 2013, 695/2013, ES:TS:2013:4490, FJ 2.

39 Sentencia del Tribunal Constitucional de 8 de julio de 2002, 154/2002, FJ 8.

40 Sentencia del Tribunal Supremo de 18 de julio de 2012, 644/2012, ES:TS:2012:5351, FJ 22. En esta línea, véase también la reciente Sentencia del Tribunal Supremo de 24 de enero de 2018, 39/2018, ES:TS:2018:145, FJ 1. 


\section{5. ¿̇CÓMO SE TRANSMITE?}

La regla general es la remisión directa entre autoridades competentes, de manera que una vez emitida la OEI por la autoridad española, esta debe dirigirla a la autoridad que corresponda del Estado ejecutante — según los arts. 7.1. de la directiva y 8.1 de la Ley 23/2014 - . A pesar de ello, la directiva contempla alternativamente que dicha remisión pueda asimismo realizarse a través de una autoridad central expresamente designada. Esta opción se ha previsto en el art. 6.3 de la Ley 23/2014, en virtud del cual es autoridad central en España el Ministerio de Justicia, a quien «corresponde la función de auxilio a las autoridades judiciales». Pero ¿qué sucede si el emisor desconoce a quién debe transmitir la orden? En este caso, el apdo. quinto del art. 7 de la directiva establece que la autoridad de emisión realizará las averiguaciones necesarias, previendo la posibilidad de acudir a los puntos de contacto de la Red Judicial Europea ${ }^{41}$, Eurojust ${ }^{42}$ $\mathrm{u}$ otros canales utilizados por las autoridades judiciales o policiales ${ }^{43}$ para obtener la información del Estado ejecutante. Y añade, en el apartado siguiente, que cuando la autoridad del Estado ejecutante que reciba una OEI no sea competente para reconocerla y adoptar las medidas necesarias para su ejecución, deberá transmitirla de oficio a la que sí lo sea y notificarlo a la autoridad de emisión ${ }^{44}$.

41 Para más información véase https://www.ejn-crimjust.europa.eu/ejn/.

42 Véase para más información http://www.eurojust.europa.eu/Pages/languages/es.aspx. Sobre Eurojust como instrumento de cooperación penal de la Unión Europea, véase Martín y Bujosa (2016: 87-113).

43 Estos mecanismos de coordinación y cooperación entre autoridades judiciales son señalados en el considerando 13 de la directiva y en el art. 9 de la Ley 23/2014. Este último se concreta en la obligación de transmisión de información y la petición de asistencia a Eurojust de acuerdo con lo establecido en la Ley 16/2015, de 7 de julio, por la que se regula el estatuto del miembro nacional de España en Eurojust, los conflictos de jurisdicción, las redes judiciales de cooperación internacional y el personal dependiente del Ministerio de Justicia en el exterior, así como su normativa de desarrollo (BOE 162, de 8 de julio de 2015, p. 56554). Sobre estos instrumentos ahonda Bachmaier Winter (2016: 5-7). Adicionalmente destacamos el reciente Acuerdo de 27 de septiembre de 2018, del Pleno del Consejo General del Poder Judicial, por el que se aprueba el Reglamento $1 / 2018$, sobre auxilio judicial internacional y redes de cooperación judicial internacional, que integra todas las disposiciones que incidan en la organización y gestión de la actuación de los órganos judiciales españoles en materia de cooperación jurisdiccional internacional, así como todas aquellas que perfilen el papel que debe desempeñar en este cometido el Servicio de Relaciones Internacionales del Consejo General del Poder Judicial (BOE 249, de 15 de octubre de 2018, p. 100017).

44 En este último sentido se pronuncia igualmente De la Parte Polanco (2015: 2). 
Además, tanto el legislador europeo como el español han querido hacer depender el éxito de la transmisión de la OEI de otra formalidad legal: su realización por cualquier medio que deje constancia escrita en condiciones que permitan al Estado de ejecución acreditar su autenticidad. En este punto debe indicarse que los conflictos surgidos respecto de la transmisión o autenticidad de la documentación necesaria para ejecutar la OEI serán resueltos a través de la comunicación directa entre las autoridades judiciales implicadas o, en su caso, mediante la intervención de las correspondientes autoridades centrales (arts. 7.7 de la directiva y 8.1.II de la Ley 23/2014).

\section{FORMA Y CONTENIDO}

Previo análisis del asunto que ahora nos ocupa se hace ineludible hacer una breve alusión a los arts. 7 y 188 de la Ley 23/2014, para aclarar la forma de la OEI, debiéndose valorar si esta es un certificado o bien un formulario. Al respecto observamos que para el caso de que una autoridad judicial española dicte una resolución penal (auto) que precise de la práctica de prueba transfronteriza a través de la OEI, el legislador nacional ha optado por su documentación mediante formulario - del mismo modo que se prevé para la orden europea de detención y entrega y la orden europea de protección- La consecuencia de ello es que, a diferencia de lo que sucede con el certificado, no será necesario enviar el testimonio de la resolución judicial penal junto con el formulario.

El contenido de la OEI lo encontramos regulado en los arts. 5 de la directiva y 188 de la Ley 23/2014. Siguiendo ambos preceptos la OEI se emitirá utilizando el formulario que figura en el anexo A y XIII, respectivamente, en el que constará la firma de la autoridad emisora. Además, las informaciones que contenga el formulario deberán ser certificadas como exactas y correctas por la propia autoridad de emisión.

En particular, el formulario de emisión incorporará la siguiente información $^{45}$ : a) los datos de la autoridad de emisión y, cuando proceda, de la autoridad validadora; b) el objeto y los motivos de la OEI; c) la información necesaria sobre la persona o personas afectadas; d) la descripción de la conducta delictiva que es objeto de la investigación o proceso y las disposiciones aplicables del Derecho penal del Estado de emisión; e) la descripción de la medida o medidas de investigación que se solicitan y de las pruebas a obtener.

A este contenido mínimo, el legislador español exige adicionalmente a la autoridad judicial competente que haga constar las formalidades, procedimientos

45 Sobre cada uno de los indicados contenidos de la directiva se pronuncia Martínez García (2016: 58-65). 
y garantías cuya observancia solicita que sean respetadas por el Estado de ejecución (art. 188.1.f de la Ley 23/2014).

Finalmente, es objeto de consideración de este punto el idioma de emisión de la OEI. A pesar de la recomendación que hace el considerando 14 de la directiva a los Estados para que, además de su lengua o lenguas oficiales, incluyan, como mínimo, otra de uso común de la Unión, esta es una potestad - y no una exigencia - del art. 5.2 de la directiva. De este modo, será suficiente con que cada Estado indique su idioma oficial, que será el que, en todo caso, deberán utilizar los Estados miembros para remitirle una OEI.

Asentada la anterior premisa, cuando una autoridad judicial emita una OEI traducirá el correspondiente formulario a la lengua oficial del Estado miembro al que se dirija, a no ser que dicho Estado hubiera indicado su aceptación en alguna de las lenguas oficiales de las instituciones comunitarias, en cuyo caso podrá asimismo remitirla en tal idioma (art. 5.3 de la directiva). A ello el art. 7.3 de la Ley 23/2014 añade la posibilidad que el idioma de emisión sea también el español en caso de existencia de una disposición convencional que lo permita.

En nuestra opinión, facilitaría de manera considerable el procedimiento de emisión de una OEI que los Estados miembros, además de su idioma oficial (o cualquier otra lengua oficial de la UE), aceptaran también las traducciones de la OEI al inglés, ya que es el idioma más utilizado por los Estados miembros de la UE ${ }^{46}$.

\section{INTRODUCCIÓN DE LAS PRUEBAS EN EL PROCESO PENAL ESPAÑOL}

Los arts. 13 de la directiva y 211 de la Ley 23/2014 exigen que el Estado de ejecución traslade de manera inmediata al Estado de emisión las pruebas que se hayan obtenido tras la ejecución de la OEI. Una vez recibido el resultado de las pruebas o medidas practicadas, la autoridad judicial española deberá introducirlas en el proceso penal.

\section{APLICACIÓN DE LAS NORMAS DE DERECHO INTERNO}

En virtud del art. 1.1 de la directiva y del art. 186.1 de la Ley 23/2014, podrá dictarse una OEI tanto para obtener pruebas que obren en poder de las autoridades competentes del Estado de ejecución como para practicar

46 Véase https://bit.ly/2IICZRZ. 
medidas de investigación. De este modo se pone de manifiesto la posibilidad de activar este mecanismo de reconocimiento mutuo en cualquier fase del proceso penal a efectos de obtención de pruebas. Se explica así que la citada norma española aclare, en el apdo. primero de su art. 187, que sean autoridades de emisión los jueces o tribunales que conozcan del proceso penal en el que se debe adoptar la medida de investigación — fase de instrucción - y los que hayan admitido la prueba cuando el procedimiento se encuentre en fase de enjuiciamiento. Ante esta realidad se pueden plantear dos escenarios distintos respecto de la introducción en el proceso penal español de la prueba procedente de otro Estado miembro: cuando lo que se obtenga sea una prueba o bien cuando se trate del resultado de una medida de investigación.

El primero de ellos se presenta cuando las autoridades competentes del Estado de ejecución deban remitir las pruebas que ya estén en su poder al órgano judicial español que corresponda. Ello sucederá, siguiendo el dictado del preámbulo II de la ley de transposición, por ejemplo, cuando la autoridad española competente pretenda el traslado temporal o la realización de una comparecencia por videoconferencia de una persona que se encuentre en el Estado de ejecución (art. 197 de la Ley 23/2014), a efectos de su declaración como testigo o perito en el juicio oral ${ }^{47}$, siendo esta última opción más beneficiosa para quien deba declarar, al evitar tener que desplazarse a España.

Sin embargo, la ley de transposición nada dice sobre cómo introducir la prueba obtenida en otro Estado miembro en el proceso penal español, ni tampoco lo hace la directiva. Este vacío legal encuentra cobertura en la doctrina jurisprudencial del TEDH, quien afirma que, además de que la admisibilidad de las pruebas depende de las normas del derecho interno, corresponde a los tribunales nacionales apreciar la fuerza probatoria de las pruebas practicadas ${ }^{48}$. En consecuencia, cuando la obtención de pruebas se produzca durante la fase de enjuiciamiento, entendemos que estas tendrán la misma consideración, a efectos de su práctica, que las pruebas obtenidas en España, debiéndolas en

47 No obstante, debe tenerse en cuenta que cuando el traslado de la persona sea a efectos de su enjuiciamiento, con inclusión de su puesta a disposición de un órgano jurisdiccional para ser sometida a juicio, en lugar de la OEI deberá emitirse una orden europea de detención y entrega (preámbulo II.5).

48 Sentencia TEDH de 20 noviembre de 1989, Kostovski vs. Países Bajos, ECHR 198921: «39. Hay que recordar de entrada que la admisibilidad de las pruebas depende, en primer lugar, de las normas del Derecho interno (Sentencia Schenk de 12 julio 1988 [TEDH 1988\4], serie A, núm. 140, pg. 29, ap. 46). De la misma manera, corresponde en principio a los tribunales nacionales apreciar la fuerza probatoria de las practicadas (Sentencia Barbera, Messegué y Jabardo de 6 diciembre 1988 [TEDH 1988\1], serie A, núm. 146, pg. 31, ap. 68)». 
todo caso valorar el órgano judicial de conformidad con las reglas de la LECrim.

El segundo escenario se plantea cuando lo que deba remitirse sea el resultado de las medidas de investigación practicadas por la autoridad competente del Estado de ejecución. En este caso, y como ya hemos indicado, durante la fase de instrucción (art. 299 LECrim), un juez español puede solicitar la práctica de cualquier diligencia de investigación prevista en la LECrim a otro Estado miembro para, posteriormente, introducir los resultados obtenidos en el proceso penal. Así, por ejemplo, sucede cuando el juez de instrucción acuerda mediante auto la intervención de las comunicaciones en otro Estado miembro y precise para ello de asistencia técnica (art. 202.1 de la Ley 23/2014).

Cuando se remita el resultado de la medida de investigación, este pasará a formar parte del acervo instructor, junto con el resto de las diligencias practicadas. Concluida la instrucción, el órgano judicial decidirá si abre el juicio oral o sobresee la causa (arts. 622, 632 y 779.1 LECrim). El problema se plantea cuando quiere utilizarse el resultado de una diligencia de investigación, por lo tanto, también la derivada de una OEI, como prueba en el juicio oral ${ }^{49}$.

En este contexto, debemos recordar que las medidas de investigación carecen de valor probatorio, motivo por el cual el juez sentenciador no puede utilizarlas, de entrada, para enervar la presunción de inocencia ${ }^{50}$. Con carácter general, solo tienen la consideración de prueba las practicadas en el acto del juicio oral ante el juez sentenciador y con la debida contradicción, cumpliendo de este modo con «la triple exigencia constitucional de toda actividad probatoria: publicidad, inmediación y contradicción $»^{51}$. En este sentido, la relevante STC 68/2010, de 18 de octubre ${ }^{52}$, recuerda

que, como regla general, sólo pueden considerarse pruebas que vinculen a los órganos de la justicia penal las practicadas en el juicio oral, pues el procedimiento probatorio ha de tener lugar necesariamente en el debate contradictorio que en forma oral se desarrolle ante el mismo Juez o Tribunal que ha de dictar Sentencia; de manera que la convicción sobre los hechos enjuiciados se alcance en contacto directo con

49 Este problema ha sido asimismo advertido por Guzmán Fluja (2006: 193-198).

50 Las diferencias entre prueba y diligencia de investigación han sido objeto de análisis, entre otros, por Fernández-Gallardo (2015: 127-128) y González Jiménez (2014: 340-341).

51 Sentencia del Tribunal Constitucional de 8 de octubre de 2014, 165/2014, ES:TC:2014: 165, FJ 2; y Sentencia del Tribunal Supremo de 16 de mayo de 2018, 225/2018, ES:TS:2018:1727, FJ 3.

52 Sentencia del Tribunal Constitucional de 18 de octubre de 2010, 68/2010, ES:TC:2010:68, FJ 5. 
los medios de prueba aportados a tal fin por las partes (por todas, SSTC 182/1989, de 3 de noviembre, FJ 2; 195/2002, de 28 de octubre, FJ 2; 206/2003, de 1 de diciembre, FJ 2; 1/2006, de 16 de enero, FJ 4; 345/2006, de 11 de diciembre, FJ 3$)^{53}$.

A pesar de ello, como en toda regla general, existe una excepción, que avala el valor probatorio de las diligencias de investigación cuando concurran determinados requisitos, que en todo caso han de ser interpretadas restrictivamente, y que tanto el TS como el TC se han encargado de concretar ${ }^{54}$. Así, en la referida STC 68/2010, de 18 de octubre, se expresa

esa idea no puede entenderse de manera tan radical que conduzca a negar toda eficacia probatoria a las diligencias judiciales y sumariales practicadas con las formalidades que la Constitución y el ordenamiento procesal establecen, siempre que puedan constatarse en el acto de la vista y en condiciones que permitan a la defensa del acusado someterlas a contradicción [SSTC 187/2003, de 27 de octubre, FJ 3; 1/2006, FJ 4; 344/2006, de 11 de diciembre, FJ 4 b)]. En este sentido, ya desde la STC 80/1986, de 17 de junio, FJ 1, nuestra doctrina ha admitido, también expresamente, que dicha regla general permite determinadas excepciones a través de las cuales es conforme a la Constitución, en limitadas ocasiones, integrar en la valoración probatoria el resultado de las diligencias sumariales de investigación si las mismas se someten a determinadas exigencias de contradicción ${ }^{55}$.

53 Esta es la doctrina asentada por el Tribunal Constitucional, tal y como el propio órgano reconoce, entre otras, en su Sentencia de 8 de octubre de 2014, 165/2014, ES:TC:2014:165, FJ 2, que la aplica en idénticos términos. Recuerda esta regla básica de la doctrina constitucional nuestro Tribunal Supremo su Sentencia de 5 de abril de 2016, 270/2016, ES:TS:2016:1553, FJ 1 del recurso interpuesto por el acusado Luis Urbano, que insiste en que "las únicas pruebas de cargo que pueden ser valoradas» son las que se practican en el juicio oral de acuerdo con «los principios de oralidad, inmediación y contradicción», no pudiendo desprenderse tal consideración de las diligencias de investigación, cuya práctica se desarrolla durante la instrucción con la finalidad de "preparar la decisión sobre la apertura del juicio oral e identificar y asegurar los medios de prueba».

De este modo lo ha reconocido y recogido en su propia doctrina jurisprudencial el TS, destacando sus sentencias de 5 de abril de 2016, 270/2016, ES:TS:2016:1553, FJ 1 del recurso interpuesto por el acusado Luis Urbano; y de 13 de octubre 2016, 762/2016, ES:TS:2016:4418, FJ 6. A nivel doctrinal, así lo constata González Jiménez (2014: 359) cuando indica que la incorporación en el juicio oral de las fuentes de prueba que derivan de las medidas de investigación realizadas durante la fase de instrucción debe ser excepcional.

Igualmente se pronuncia la Sentencia del TEDH de 20 noviembre de 1989, Kostovski vs. Países Bajos, ECHR 1989-21: «41. Las pruebas deben ser presentadas, 
Estos requisitos se clasifican, como recuerda la reciente STS 225/2018, de 16 de mayo ${ }^{56}$, en

materiales (su imposibilidad de reproducción en el acto del juicio oral), subjetivos (la necesaria intervención del Juez de Instrucción), objetivos (que se garantice la posibilidad de contradicción y la asistencia letrada el imputado, a fin de que pueda interrogar al testigo) y formales (la introducción del contenido de la declaración sumarial a través de la lectura del acta en que se documenta, conforme al art. 730 LECrim, o a través de los interrogatorios).

Precisamente a este último requisito dedicaremos nuestra atención en el siguiente epígrafe por cuanto posibilita que el resultado de la diligencia de investigación «acceda al debate procesal público y se someta a contradicción en el juicio oral ante el Juez o Tribunal sentenciador».

\section{CAUCE PROCESAL PARA INTRODUCIR LAS MEDIDAS DE INVESTIGACIÓN AL PROCESO PENAL}

\subsection{La vía del art. 730 LECrim}

Dispone el art. 730 LECrim que «podrán también leerse o reproducirse a instancia de cualquiera de las partes las diligencias practicadas en el sumario, que, por causas independientes de la voluntad de aquéllas, no puedan ser reproducidas en el juicio oral».

Con carácter preliminar, debemos destacar que nuestra doctrina judicial se ha referido mayoritariamente a la aplicación del art. 730 LECrim en relación

en principio, en presencia del acusado y en audiencia pública, de cara a un juicio contradictorio. (Sentencia Barbera, Messegué y Jabardo, anteriormente citada, serie A, núm. 146, pg. 34, ap. 78). No significa esto que la declaración de un testigo deba hacerse siempre ante el tribunal y en público para que pueda utilizarse como prueba: si se utilizan declaraciones prestadas en la fase de la instrucción preparatoria no se infringen los apartados 3.d) y 1 del artículo 6 , sin perjuicio de que se respeten los derechos de la defensa. Por regla general, estos derechos exigen que se dé al acusado una ocasión adecuada y suficiente para oponerse e interrogar al testigo, en el momento en que declare o más tarde (véase, mutatis mutandis, Sentencia Unterpertinger de 24 noviembre 1986 [TEDH 1986\14], serie A, núm. 110, pgs. 14 y 15, ap. 31)».

56 Sentencia del Tribunal Supremo de 16 de mayo de 2018, 225/2018, ES:TS:2018:1727, FJ 3. 
con las declaraciones testificales ${ }^{57}$. A pesar de ello, teniendo en cuenta que la literalidad de esta norma hace referencia a «las diligencias practicadas en el sumario» - y no exclusivamente a los interrogatorios de testigos-, entendemos que debe hacerse una interpretación flexible de esta norma de modo que también pueda incorporarse por esta vía el resultado de cualquier otra medida de investigación (Cerrato Guri, 2017: 519-529), que deberá introducirse en el juicio oral a través del pertinente medio de prueba ${ }^{58}$.

Por lo tanto, y aunque ello no se desprenda de la literalidad del art. 730 LECrim $^{59}$, el TS reconoce que este es el cauce que el legislador ha previsto para dar validez probatoria a las diligencias de instrucción, y así lo ha declarado expresamente en su reciente Sentencia 225/2018, de 16 de mayo ${ }^{60}$, al señalar que «el artículo 730 de la Ley de Enjuiciamiento Criminal constituye uno de los excepcionales cauces para conferir validez como elemento de prueba al contenido de diligencias practicadas antes del juicio oral, fuera del marco general del artículo 741 de la misma y sin vulnerar la garantía constitucional de presunción de inocencia solamente enervable, en principio, por prueba lícita y practicada en juicio oral y público». Más ampliamente, el TC ha admitido la legitimidad constitucional del art. 730 LECrim, siendo de destacar su Sentencia $345 / 2006^{61}$, en virtud de la cual:

57 Véanse como ejemplo, las recientes sentencias del Tribunal Supremo de 22 de marzo de 2017, 182/2017, ES:TS:2017:1061; y de 5 de abril de 2016, 270/2016, ES:TS:2016:1553.

58 Sobre esta cuestión Fernández-Gallardo (2015: 127-128) ha concretado que "para que puedan ser valorados los elementos probatorios que de estas diligencias pudiesen derivarse deben incorporarse al juicio oral mediante un medio probatorio aceptable en derecho, como por ejemplo la declaración testifical de los agentes intervinientes debidamente practicada en el juicio con las garantías de la contradicción y la inmediación». Por lo tanto, en este caso, la prueba será la declaración en el juicio oral del policía que practicó la medida de investigación. En esta línea, para González Jiménez (2014: 350) «una mala o inadecuada selección de los medios probatorios para aportar las fuentes de prueba puede provocar su inadmisión por parte del Tribunal sentenciador, o impedir su valoración».

59 Al respecto González Jiménez (2014: 360) critica la falta de regulación en la LECrim, y en consecuencia la inexistencia de unos estándares claros, de cómo incorporar el resultado de una diligencia en el juicio oral como prueba.

60 Sentencia del Tribunal Supremo de 16 de mayo de 2018, 225/2018, ECLI:ES:TS: 2018:1727, FJ 3.

61 Sentencia del Tribunal Constitucional de 11 de diciembre de 2006, 345/2006, FJ 3. En la misma línea, véase la Sentencia del Tribunal Constitucional de 18 de octubre, 68/2010, ES:TC:2010:68, FJ 5. 
En aplicación de esta doctrina hemos admitido expresamente en anteriores pronunciamientos la legitimidad constitucional de las previsiones legales recogidas en los arts. 714 y 730 LECrim, siempre que el contenido de la diligencia practicado en el sumario se reproduzca en el acto del juicio oral mediante la lectura pública del acta en la que se documentó, o introduciendo su contenido a través de los interrogatorios (STC 2/2002, de 14 de enero), pues de esta manera, ante la rectificación o retroacción del testimonio operada en el acto del juicio oral (art. 714 LECrim), o ante la imposibilidad material de su reproducción (art. 730 LECrim) el resultado de la diligencia accede al debate procesal público ante el Tribunal [...]. De esta forma se posibilita que el contenido de la diligencia se someta a confrontación con las demás declaraciones de los intervinientes en el juicio oral.

En consecuencia, podrá tener validez probatoria aquella diligencia de investigación que se reproduzca en el juicio oral a través de la lectura del acta que la documentó o por medio del interrogatorio de quien la practicó, dando de este modo cumplimiento a la ineludible «triple exigencia constitucional de toda actividad probatoria: publicidad, inmediación y contradicción».

A mayor abundamiento, el TC y el TS han reconocido la naturaleza preconstituida de la prueba que resulta de las medidas de investigación introducidas en el juicio oral por la vía del art. 730 LECrim. Por su claridad expositiva destacamos la STS 225/2018 ${ }^{62}$, que da «validez como prueba de cargo preconstituida [a] las declaraciones prestadas en fase sumarial». De hecho, esta resolución judicial considera "prueba preconstituida» aquellas «diligencias sumariales de imposible repetición en el Juicio Oral por razón de su intrínseca naturaleza, y cuya práctica, como sucede con una inspección ocular y con otras diligencias, es forzosamente única e irrepetible» ${ }^{63}$. Igualmente se ha preocupado de definir el término "prueba preconstituida» la doctrina procesal, siendo de destacar la aportación de Gimeno Sendra (2010: 38) respecto de su

62 Sentencia del Tribunal Supremo de 16 de mayo de 2018, 225/2018, ES:TS:2018:1727, FJ 3. Y en el ámbito de la doctrina constitucional, véase la Sentencia del Tribunal Constitucional de 8 de octubre de 2014, 165/2014, FJ 2.

63

Según Guzmán Fluja (2006: 203), «es común en la doctrina hablar de valor probatorio de los actos de investigación, expresión con la cual se quiere hacer ver que hay casos en los que resulta necesario elevar una diligencia de instrucción o de investigación a la categoría de prueba apta para ser utilizada en la desvirtuación de la presunción de inocencia. Esta necesidad suele justificarse en el hecho de que se produce una situación de irrepetibilidad o de irreproducibilidad probatoria en el juicio oral, de manera que debe acudirse al material obtenido durante la investigación para poder probar los hechos». El autor deja claro que, en su opinión, no existen diligencias de investigación con valor probatorio, sino que los resultados de estas pueden ser introducidos en el juicio oral, lo que es distinto. 
consideración como prueba documental y que, dada su relevancia, transcribimos a continuación:

La prueba preconstituida es una prueba documental, que puede practicar el juez de instrucción y su personal colaborador (policía judicial y Ministerio Fiscal) sobre hechos irrepetibles, que no pueden, a través de los medios de prueba ordinarios, ser trasladados al momento de realización de juicio oral. Por ello, dicha prueba tiene un carácter aseguratorio de los indicios y fuentes de prueba, que, bajo determinadas garantías formales, de entre las que destaca la de garantizar la «posibilidad de contradicción», posibilitan su introducción en el juicio oral, a través de la lectura de documentos (art. 730), como documentos públicos oficiales suficientes para fundar una sentencia de condena. A pesar de ello, entendemos que debe completarse la anterior definición añadiendo que también puede incorporarse el resultado de una medida de investigación al juicio oral a través del interrogatorio de quien la practicó, resultando ello de la interpretación de la doctrina jurisprudencial y constitucional antes analizada.

\subsection{Su aplicación a las medidas de investigación derivadas de una OEI}

El art. 730 LECrim se desarrolló pensando en las diligencias de investigación practicadas en España. Por ello, y teniendo en cuenta nuestro objeto de estudio, nos preguntamos si su aplicación puede asimismo extenderse a las medidas practicadas en otro Estado miembro, de modo que su resultado pueda también introducirse en el juicio oral. Piénsese, por ejemplo, en una entrada y registro realizada en Francia en virtud de una OEI emitida por un juez español.

En nuestra opinión, y sobre la base de la doctrina jurisprudencial, la respuesta debe ser afirmativa. El TS ha tenido ocasión de pronunciarse últimamente sobre esta problemática ${ }^{64}$, reconociendo el valor probatorio de las declaraciones sumariales de los testigos que no comparezcan ante el tribunal por encontrarse fuera de España, siempre con la debida observancia de determinadas cautelas «que hayan sido practicadas en la instancia de forma inobjetable», siendo para ello ineludible su práctica en presencia del juez instructor, y que las defensas hayan tenido «la oportunidad, cuando ello es posible, para que acudan a la diligencia e intervengan en ella de forma que resulte precedente», garantizando de este modo la debida contradicción y, en última instancia,

64 Sentencia del Tribunal Supremo de 13 de marzo de 2018, 118/2018, ES:TS:1782/ 2017, FJ 4. 
su derecho a la defensa ${ }^{65}$. Por lo tanto, el TS reconoce el valor probatorio de las declaraciones de testigos durante la fase de instrucción. Pero ¿qué sucede con el resto de diligencias? La propia STS parte de la base de que el art. 730 LECrim «permite proceder, a instancia de cualquiera de las partes, a la lectura de las diligencias practicadas en el sumario que no puedan ser reproducidas en el juicio oral por causas independientes a la voluntad de las partes», por lo que su aplicación se extiende, como ya hemos tenido la oportunidad de señalar, a cualquier diligencia de la fase de instrucción.

Por todo ello, podemos concluir que el resultado de una medida de investigación practicada en otro Estado miembro puede igualmente introducirse en el juicio oral por la vía del art. 730 LECrim.

\section{ADMISIBILIDAD DE LAS PRUEBAS DERIVADAS DE UNA OEI}

Finalmente, tras determinar cómo introducir en el proceso penal español las pruebas y las medidas de investigación obtenidas en otro Estado miembro, es momento de examinar su admisibilidad.

Compartimos con Jimeno Bulnes (2016: 196) que el mayor escollo en la aplicación de la OEI es la admisibilidad probatoria. Esta problemática «constituye una de las mayores objeciones a la aplicación del principio de reconocimiento mutuo en el ámbito probatorio» porque hay distintos ordenamientos jurídicos nacionales que tienen diferente sensibilidad en cuanto a la vulneración de derechos fundamentales.

En relación con lo que acabamos de señalar, si bien es cierto que los Estados miembros han apostado por la OEI como mecanismo de cooperación judicial penal en materia de obtención de prueba, lográndose de este modo la aproximación de las cuestiones mínimas a tener en cuenta en el

65 Sobre el valor probatorio de la declaración de testigo fuera del juicio oral, la referida STS se ha encargado de concretar que el TC no exige que la contradicción sea efectiva y realmente practicada, sino que «el órgano judicial hubiera hecho todo lo posible por proporcionarla" y ello al considerar que "no siempre va a ser posible asegurar la presencia del acusado o de su abogado en la declaración sumarial del testigo, ya porque el mismo acusado renuncia a aprovechar la oportunidad ofrecida y no acude a la declaración, ya por otras circunstancias», evitando con ello «dejar en manos del acusado la corrección del procedimiento». Por ello afirma el TS que «no es correcto negar a priori todo valor de esta declaración», siendo el criterio del TEDH que «la ausencia de contradicción no será contraria al derecho a un proceso equitativo si en el caso concreto existían medidas que permitieran una correcta evaluación de la fiabilidad de la declaración». Sobre la "posibilidad de contradicción» véase también la Sentencia del Tribunal Supremo de 16 de mayo de 2018, 225/2018, ES:TS:2018:1727, FJ 3. 
reconocimiento y práctica de prueba transfronteriza, no es menos cierto que cada Estado miembro tiene su sistema penal propio. Ello hace inevitable la existencia de diferencias respecto de las garantías del proceso y, en última instancia, el riesgo de ocasionar problemas de licitud de la prueba practicada en el Estado de ejecución en el momento de introducirse en el proceso penal del Estado de emisión ${ }^{66}$.

Siendo esto así, la duda que se nos plantea es: ¿qué debe hacer un juez español cuando la prueba practicada en otro Estado miembro no lo ha sido de acuerdo con las garantías del proceso en España? A esta cuestión dan respuesta Martín y Bujosa (2016: 16), quienes entienden que una interpretación amplia del principio de reconocimiento mutuo implicaría una renuncia del Estado receptor — esto es, el Estado de emisión de la OEI— «a condicionar la validez de la misma a su adecuación al propio derecho interno», lo que podría conducir a un escenario atípico en relación con las garantías del debido proceso (Picó i Junoy, 2012: 159-175). Así, siguiendo el ejemplo de los autores, cuando un testigo declarase en el Estado de ejecución sin la asistencia del letrado del investigado, teniendo en cuenta que no todas las normas procesales exigen esta garantía, el juez español no tendría más opción que admitir su declaración. Para evitar esta consecuencia debería aplicarse una interpretación más restrictiva del mencionado principio "por su vinculación directa con el papel del juez nacional como corresponsable y garante de los derechos y libertades fundamentales del ciudadano» (Martín y Bujosa, 2016: 25) ${ }^{67}$. De este modo, el juez español podría dejar de introducir en el proceso penal una prueba válidamente obtenida en el Estado de ejecución, pero no acorde con las garantías procesales del art. $24 \mathrm{CE}^{68}$. En este punto, lo ideal sería fijar unas garantías procesales mínimas y comunes aplicables a toda cooperación judicial penal, cuyo incumplimiento debería poder permitir al Estado de emisión de una OEI inadmitir la prueba obtenida en el Estado de ejecución. Sin embargo, esto no se ha conseguido a

66 En este sentido se pronuncia también Martínez García (2016: 181), quien concluye que «la existencia de 26 versiones diferentes de lo que se entiende por prudencia puede traer problemas sobre la licitud de la prueba obtenida en otro Estado y puede llegar a constituir un verdadero subterfugio destinado a obviar garantías exigibles en el Estado requirente de ayuda».

67 Asimismo, en esta línea Martínez García (2016: 181-182) afirma que el principio de reconocimiento mutuo tiene como límites «los principios y reglas de la Unión Europea, los propios límites de la cooperación en materia penal y los derechos fundamentales». A esta misma cuestión se ha referido ampliamente De Hoyos Sancho (2005: 807-842).

68 Refuerza esta idea Martínez García (2016: 182-184). 
fecha de hoy, lo que pone de manifiesto la fractura de la confianza mutua entre los Estados de la UE (Martín y Bujosa, 2016: 33) ${ }^{69}$.

A pesar de todo ello, el criterio seguido por la jurisprudencia de nuestro TS es la no revisión en España del contenido de una prueba practicada en otro Estado miembro de conformidad con la legislación de este último, que deberá incorporarse en el proceso penal español sin que necesariamente tenga que ajustarse a la legalidad española ${ }^{70}$.

Esta problemática ya se planteaba con anterioridad a la directiva. En su momento, el Alto Tribunal declaró que no correspondía a la autoridad judicial española controlar la legalidad de las pruebas practicadas en otro Estado miembro, por lo que debía admitirlas directamente. Nos ilustra, en este sentido, la STS $1521 / 2002^{71}$, subrayando que

en el marco de la Unión Europea, definido como un espacio de libertad, seguridad y justicia, en el que la acción común entre los Estados miembros en el ámbito de la cooperación policial y judicial en materia penal es pieza esencial, según el art. 29 del Tratado de la Unión en la versión consolidada de Maastricht (RCL 1994, 81, 1659; RCL 1997, 917 y RCL 1999, 2661 y LCEur 1992, 2465), [que] no cabe efectuar controles sobre el valor de los realizados ante las autoridades judiciales de los diversos países de la Unión, ni menos de su adecuación a la legislación española cuando aquéllos se hayan efectuado en el marco de una Comisión Rogatoria y por tanto de acuerdo con el art. 3 del Convenio Europeo de Asistencia Judicial en materia Penal de 20 de abril de 1959 (RCL 1982, 2423; ApNDL 13560) —BOE 17 de septiembre de 1982-. En tal sentido se pueden citar las Sentencias de esta Sala 13/1995, de 19 de enero (RJ 1995, 155) en relación a Comisión Rogatoria cumplimentada por Alemania; Sentencia núm. 974/1996, de 9 de diciembre (RJ 1997, 1121) donde expresamente se proclama que «...en el ámbito del espacio judicial europeo no cabe hacer distinciones sobre garantías de imparcialidad de unos u otros Jueces ni del respectivo valor de los actos ante ellos practicados en forma...», en relación a Comisión Rogatoria ante las autoridades suecas; la STS núm. 340/2000, de 3 de marzo (RJ 2000, 1172) que en sintonía con las anteriores confirma la doctrina

69 Téngase en cuenta que todos los Estados miembros de la Unión Europea están sujetos al art. 6 TUE, de conformidad con el cual reconocen los derechos, libertades y principios enunciados en la Carta de Derechos Fundamentales de la Unión Europea y en el Convenio Europeo para la Protección de los Derechos Humanos y de las Libertades Fundamentales.

70 Sobre la admisibilidad de la prueba transfronteriza en la jurisprudencia del Tribunal Supremo, véase Rodríguez-Medel Nieto (2016: 462 y ss.).

71 Sentencia del Tribunal Supremo de 25 de septiembre de 2002, 1521/2002, RJ 200219846, FJ 1. Sigue la misma línea la reciente Sentencia del Tribunal Supremo de 3 de mayo de 2017, 313/2017, ES:TS:2017:1688, FJ 3. 
de que la incorporación a causa penal tramitada en España de pruebas practicadas en el extranjero en el marco del Convenio Europeo de Asistencia Judicial citado no implica que dichas pruebas deban ser sometidas al tamiz de su conformidad con las normas españolas; la STS núm. 1450/1999, de 18 de noviembre en relación a Comisión Rogatoria cumplimentado por las autoridades francesas, y en fin, la Sentencia núm. 947/2001, de 18 de mayo para la que «...no le corresponde a la autoridad judicial española verificar la cadena de legalidad por los funcionarios de los países indicados, y en concreto el cumplimiento por las autoridades policiales holandesas de la legalidad de aquel país ni menos sometidos al contraste de la legislación española ${ }^{72}$.

Este criterio jurisprudencial se ha mantenido en el tiempo y así lo confirma la STS 312/2012 73 , que por su relevancia traemos a colación. Con carácter preliminar, esta resolución del TS resalta la existencia de «un consolidado cuerpo jurisprudencial en relación con las consecuencias derivadas de la existencia de un espacio judicial europeo, en el marco de la Unión fruto de la comunión en unos mismos valores y garantías compartidos entre los países de la Unión, aunque su concreta positivación dependa de las tradiciones jurídicas de cada Estado, pero que en todo caso salvaguardan el contenido esencial de aquellos valores y garantías», para a continuación adentrarse en la problemática examinada con cita a la recurrente Sentencia 13/199574, que hace referencia a la práctica de una declaración testifical en el Estado de ejecución - Alemania - ante la autoridad policial y no la judicial, como exige el Estado español. Pese a ello, en este caso el TS estima correcta la prueba practicada, pues considera que

ello no le resta el valor propio de una diligencia de prueba hecha en el extranjero, razón que justifica el que no se cumplieran las exigencias propias de los principios de inmediación, publicidad y oralidad, aunque sí las concernientes al de contradicción por la posibilidad que tuvieron las partes de formular las preguntas correspondientes, y el que, debidamente incorporada a los autos, tras lo cual se produjo el nuevo señalamiento del juicio oral, adquiriera aptitud, como prueba así documentada,

72 Sobre la admisibilidad de las pruebas, antes de la entrada en vigor de la directiva, cierta doctrina autorizada entendió que esta cuestión debía ser abordada por los Estados miembros, en función de cada sistema de justicia penal, al no ser función de las instituciones europeas aprobar normas relativas a cuándo debe considerarse admisible una prueba o no. Así, véase Bachmaier Winter (2011: 602-606).

73 Sentencia del Tribunal Supremo de 24 de abril de 2012, 312/2012, ES:TS:2012:3117, FJ 2.

74 Sentencia del Tribunal Supremo de 19 de enero de 1995, 13/1995, RJ 1995\155, fundamento jurídico FJ 2. 
para que el Tribunal la pudiera valorar, como lo hizo, en unión de las demás existentes, como suficiente para contrarrestar la presunción de inocencia ${ }^{75}$.

\section{CONCLUSIONES}

Tras el estudio de la rica problemática sobre la admisibilidad de las pruebas obtenidas con la nueva OEI en el proceso penal español, podemos llegar a las siguientes tres conclusiones:

1. a) La apuesta del legislador europeo por la aproximación de las legislaciones internas en materia penal — si bien desde el respeto a las singularidades de cada Estado miembro - para dar respuesta a la grave problemática de la criminalidad transnacional, y que se ha materializado con la entrada en vigor de la Directiva 2014/41/CE del Parlamento Europeo y del Consejo de 3 de abril de 2014, relativa a la orden europea de investigación en materia penal, ha logrado lo que hasta hace poco tiempo parecía imposible: hacer realidad la cooperación judicial en materia penal a través de un instrumento de reconocimiento mutuo que permite la obtención de pruebas en todas las fases del proceso penal, en cualquier Estado miembro de la Unión Europea.

Ahora bien, para valorar la efectividad práctica de la OEI deberemos esperar al resultado del informe que, en principio, como exige el art. 37 de la directiva, la Comisión debe presentar al Parlamento Europeo y al Consejo el próximo mes de mayo de 2019. Este informe deberá incluir la evaluación de su repercusión sobre la cooperación en materia penal y en la protección de las personas, y si se considera necesario, irá acompañado de propuestas de mejora. Sin embargo, somos conscientes que para algunos Estados, como el español, la tardía transposición de la norma europea a su ordenamiento jurídico interno impedirá la obtención de una fotografía real de la aplicación de la directiva, por los escasos resultados existentes hasta el momento.

2. $\left.{ }^{a}\right)$ No obstante, y pendientes del informe que se acabe presentando, el análisis realizado en el presente trabajo nos permite ser optimistas y avanzar una valoración positiva de la OEI como mecanismo de cooperación judicial penal, por los siguientes motivos:

a) En primer lugar, la directiva introduce un valiosísimo mecanismo de reconocimiento mutuo, la OEI, que logra superar el régimen fragmentario existente hasta el momento, sustituyendo todos los instrumentos anteriores

75 Asimismo, véase la Sentencia del Tribunal Supremo de 27 de diciembre de 2006, 1281/2006, RJ 2007\588, FJ 5. 
de obtención de prueba penal transfronteriza que únicamente eran capaces de dar una solución parcial a esta cuestión.

b) En segundo lugar, con la directiva se incorpora por primera vez la posibilidad, más allá de las pruebas ya existentes en el Estado de ejecución, de practicar medidas de investigación en cualquier Estado de la Unión Europea con vistas a la obtención de pruebas, permitiéndose de esta forma también la colaboración entre los Estados miembros durante la fase de instrucción del proceso penal.

c) Podemos concluir también que la incorporación de los resultados obtenidos de la práctica de una OEI variará en función de si lo que se remite es una prueba ya existente en el Estado de ejecución o si es el resultado de una medida de investigación realizada en dicho Estado. En el primero de los casos, las pruebas remitidas por la autoridad competente del Estado ejecutor merecen la misma consideración que las que se obtienen en España, debiéndolas en todo caso valorar el órgano judicial de conformidad con las reglas de la LECrim, pues como ha señalado el TEDH corresponde a los tribunales nacionales apreciar la fuerza probatoria de las pruebas practicadas en el extranjero. En cambio, en el segundo caso, el resultado de la medida de investigación que pretenda introducirse en el juicio oral con eficacia probatoria deberá hacerse, como expresamente han reconocido el TS y el TC, por el cauce del art. 730 LECrim, del mismo modo que las diligencias de investigación realizadas en territorio español, ya sea a través de la lectura del acta que las documentó o por medio del interrogatorio de quien las practicó. Se cumplen así los principios de publicidad, inmediación y contradicción que deben regir en toda actividad probatoria.

d) Por último, una de las cuestiones más controvertidas que suscitaba la propuesta de directiva era el desequilibrio entre las partes procesales respecto de la solicitud de una OEI, en perjuicio del investigado o encausado. Ello lo soluciona el vigente apdo. tercero del art. 1 de la directiva, legitimando expresamente a la parte pasiva del proceso penal para solicitar la emisión de una OEI, garantizándose así el respeto a su derecho de defensa.

3. a) A pesar de todas las ventajas que se desprenden de la entrada en vigor de la directiva y la posterior ley de transposición española, que recientemente ha incorporado la OEI como instrumento de reconocimiento mutuo al ordenamiento jurídico español, todavía existen, en nuestra opinión, algunos aspectos a mejorar:

a) La primera crítica es para el legislador español quien, a sabiendas de que el Ministerio Fiscal carece, a fecha de hoy, de competencia para dirigir la instrucción penal en el genérico marco de los procedimientos desarrollados en la LECrim, lo reconoce como autoridad de emisión de órdenes europeas de investigación en los procedimientos que dirija, siempre que la medida que 
contenga la OEI no sea limitativa de derechos fundamentales. A nuestro juicio, el legislador desaprovechó en su momento una magnífica oportunidad para realizar una reforma integral del proceso penal y, con ella, atribuir al fiscal la dirección de la fase de instrucción, siendo consecuencia de ello la imposibilidad de emitir una OEI, con carácter general. La única salvedad la encontramos en el proceso penal especial de menores, que sí le atribuye expresamente competencia para dirigir la investigación de los hechos. Por lo tanto, entendemos que los fiscales únicamente podrán emitir órdenes europeas de investigación cuando el investigado sea un menor y la medida no sea limitativa de derechos fundamentales.

b) La segunda cuestión concierne a la admisibilidad de la prueba resultante de la ejecución de una OEI y su afectación a las garantías constitucionales del proceso español. En concreto, la problemática se plantea cuando la autoridad competente del Estado de ejecución, que ha reconocido la OEI emitida por un juez español, obtiene las pruebas o practica las medidas de investigación en ella solicitadas de conformidad con su ordenamiento jurídico interno y este no contempla las mismas garantías procesales reconocidas en el orden constitucional español. Si bien reconocemos que lo ideal sería que el juez español pudiera exigir, con la emisión, el cumplimento de las garantías mínimas del art. 24 CE para su incorporación al proceso penal, somos conscientes también de que ello dificultaría la finalidad de la cooperación judicial en materia de prueba transfronteriza. Por este motivo entendemos acertada la solución que ha dado el TS a esta compleja realidad y que, en última instancia, facilita la tan anhelada cooperación judicial penal, apostando por la no revisión en España del contenido de una prueba practicada en otro Estado miembro cuando esta se haya realizado respetando la legalidad de este último, de modo que el juez español deberá incorporarla al proceso penal, aun cuando no se ajustara a la legalidad española.

\section{Bibliografía}

Arangüena Fanego, A. (2010). De «la Orden Europea de Vigilancia» al Reconocimiento Mutuo de Resoluciones Judiciales sobre Medidas Sustitutivas de la prisión provisional: primera aproximación a la Decisión Marco 2009/829/JAI del Consejo. En C. Arangüena Fanego (dir.). Espacio Europeo de Libertad, Seguridad y Justicia: últimos avances en cooperación judicial. Valladolid: Lex Nova.

Bachmaier Winter, L. (2011). La orden europea de investigación: la propuesta de Directiva europea para la obtención de prueba en el proceso penal. Revista Española de Derecho Europeo, 37, 71-93. 
- (2016). La cooperación judicial penal. En J. M. Beneyto Pérez (dir.). Tratado de Derecho y Politicas de la Unión Europea. Tomo VIII. Ciudadanía europea y espacio de libertad, seguridad y justicia. Pamplona: Aranzadi.

Burgos Ladrón de Guevara, J. (2016). La orden de investigación penal en España: aplicación y contenido. Posible relación con la orden europea de protección. En M. Jimeno y J. Pérez (coords.). Nuevos horizontes del derecho procesal (pp. 519524). Barcelona: J. M. Bosch.

Casanova Martí, R. (2014). Las intervenciones telefónicas en el proceso penal. Barcelona: J. M. Bosch.

Cerrato Guri, E. (2017). La dificultad probatoria del delito de maltrato sobre la mujer. En J. Picó i Junoy (dir.). Peritaje y prueba pericial (pp. 519-529). Barcelona: J. M. Bosch.

De Hoyos Sancho, M. (2005). El principio de reconocimiento mutuo de resoluciones penales en la Unión Europea: ‘asimilación automática o corresponsabilidad? Revista de Derecho Comunitario Europeo, 22, 807-842.

De la Parte Polanco, M. (2015). Algunas cuestiones sobre la Orden Europea de Investigación. Aranzadi digital, 1/2015 [BIB 2015/4851].

Fernández-Gallardo, J. A. (2015). Cuestiones actuales de proceso penal. Madrid: Dykinson.

García García, T. (2018). La cooperación jurídica internacional en la persecución del delito de trata de seres humanos. Especial consideración a los equipos conjuntos de investigación. Revista Aranzadi Unión Europea, 3, 4.

García Sánchez, B. (2012). Pluralismo constitucional en la Unión Europea y heterogeneidad de las normativas penales de los estados miembros: problemas del principio de reconocimiento mutuo. Cuadernos de Politica Criminal, 106, 191-222.

Gimeno Sendra, V. (2010). La prueba preconstituida de la policía judicial. Revista catalana de seguretat pública, 22, 37-67.

González Jiménez, A. (2014). Las diligencias policiales y su valor probatorio. Barcelona: J. M. Bosch.

Guzmán Fluja, V. C. (2006). Anticipación y preconstitución de la prueba en el proceso penal. Valencia: Tirant lo Blanch.

Jimeno Bulnes, M. (2011). Un proceso europeo para el siglo XXI. Cizur Menor: Thomson Reuters.

_- (2016). Orden europea de investigación en materia penal. En M. Jimeno Bulnes (dir). Aproximación legislativa versus reconocimiento mutuo en el desarrollo del espacio judicial europeo: una perspectiva multidisciplinar (pp. 151-208). Barcelona: J. M. Bosch.

Martín García, A. L. y Bujosa Vadell, L. (2016). La obtención de prueba en materia penal en la Unión Europea. Barcelona: Atelier.

Martínez García, E. (2016). La orden europea de investigación: actos de investigación, ilicitud de la prueba y cooperación judicial transfronteriza. Valencia: Tirant lo Blanch. 
Picó i Junoy, J. (2012). Las garantías constitucionales del proceso (2. ${ }^{\mathrm{a}}$ ed.). Barcelona: J. M. Bosch.

Rodríguez-Medel Nieto, C. (2016). Obtención y admisibilidad en España de la prueba penal transfronteriza. Cizur Menor: Aranzadi. 